\title{
ARTE E CONHECIMENTO: UMA ABORDAGEM PARA O TEATRO NA EDUCAÇÃO
}

\section{ART AND KNOWLEDGE: AN APPROACH FOR THEATER IN EDUCA- TION}

DOI: $\underline{\text { http://dx.doi.org/10.5965/1984317815022019078 }}$

Libéria Rodrigues Neves

Universidade Federal de Minas Gerais

liberianeves@gmail.com

\begin{abstract}
RESUMO
Por que arte na educação? As respostas podem ser muitas, advindas de diversos campos de saber, para além, inclusive, do próprio campo da arte. Este ensaio busca abordar a experiência artística como ação cognitiva, de modo a fomentar as discussões que sustentem a presença e permanência das artes, em especial o teatro, na educação. Para tal, propõe uma discussão a parir de pressupostos teóricos - acerca da base metafórica da Cognição Imaginativa (Arthur Efland); da experiência artística como ação globalizadora de conhecimentos (Fernando Hernández); da imaginação como produto e processo de uma materialização estética constituída pela organização singular dos recursos simbólicos socialmente construídos (Vygotsky). Busca destacar a experiência cênica como espaço de conhecimento e produção de sentido, bem como possibilidade de ação, em ampliadas dimensões (Augusto Boal).
\end{abstract}

Palavras-chave: Arte. Teatro. Conhecimento. Cognição. Imaginação.

\begin{abstract}
Why arts in education? There can be many answers, coming from several knowledge fields, going even beyond the very field of art. This essay seeks to approach the artistic experience as a cognitive action, in order to promote discussions that support the presence and permanence of arts, in special theater, in education. For such, we propose a discussion from theoretical framework - about the metaphoric base of Imaginative Cognition (Arthur Efland); of artistic experience as knowledge globalizing action (Fernando Hernández); of imagination as product and process of an aesthetic materialization constituted by the singular organization of symbolic resources socially constructed (Vygotsky). The essay seeks to emphasize the scenic experience as a space of knowledge and meaning construction, as well as a possibility for action, in amplified dimensions (Augusto Boal).
\end{abstract}

Keywords: Arts; Theater; Knowledge; Cognition; Imagination. 


\section{INTRODUÇÃO}

Qual teria sido o primeiro ato artístico praticado pelo homem? O teatrólogo brasileiro Augusto Boal sempre entendeu que foi o teatro, ao demonstrar que este nasce quando o ser humano descobre que pode ver-se no ato de ver - ver-se em situação. Portanto, Boal (2002) afirma que o teatro representa a primeira invenção humana, aquela que possibilita e promove todas as outras invenções, as outras descobertas e as outras artes.

Desse modo, o homem inventou a pintura porque antes inventara o teatro; ou seja, quando caçou um bisonte, se viu caçando e, por isso, fez-se possível pintar no teto da caverna a imagem de um caçador - ele mesmo - no ato de caçar. Quando se viu emitindo sons, foi capaz de imitar animais, de descobrir variante em seu imitar e compor.

Boal conclui sua obra, composta de mais de vinte títulos, afirmando e defendendo que o ser torna-se humano quando inventa o teatro - uma atividade vocacional de todos os seres falantes. Essa é a visão do artista.

O arqueólogo inglês Steven Mithen (2002), em sua obra A pré-história da mente: uma busca das origens da arte, da religião e da ciência, destaca o aparecimento da arte como fruto de um big bang cultural ocorrido na transição do período Paleolítico. Atribui essa aparição a uma grande reformulação do projeto da mente. Os humanos, há cerca de 40 mil anos, passaram a relacionar seus domínios cognitivos possibilitando a criação intencional de marcas ou objetos com formas preconcebidas. Tais atividades, segundo o arqueólogo, tornaram-se possíveis a partir da conquista de alguns atributos mentais; entre eles: 1) a produção de uma imagem visual envolvendo o planejamento e a execução de um molde mental preconcebido; 2) a comunicação intencional com referência a um evento ou objeto não presente; 3) a atribuição de um significado a uma imagem visual não associada com seu referente (p. 258-259).

Desse modo, o humano passou a alcançar a possibilidade de fazer um distanciamento temporal e espacial entre o símbolo e seu referente. Seria esse big bang fruto da capacidade de o homem ver-se no ato de ver - em situação? O cientista e o artista estarão dizendo a mesma coisa em linguagens diferentes? Fato é 
que a arte surgiu como produção cultural desde então, perdurando até hoje. Por que e para que o ser falante produz arte?

Ernest Fischer, poeta, escritor, filósofo e jornalista, em seu clássico A necessidade da arte (1981), concebe-a como substituto da vida; como uma forma de colocar o homem em estado de equilíbrio com o meio circundante. Assim, propõe uma discussão acerca da natureza da arte e sua necessidade.

Inspirado por uma influência marxista, Fischer (1981) contribui para pensar que toda arte vê-se condicionada por seu tempo e representa a humanidade em consonância com as ideias e aspirações, as necessidades e as esperanças de uma situação histórica particular.

Conclui, portanto, que a arte se faz necessária para que o homem se torne capaz de conhecer e mudar o mundo. Mas também se mostra necessária em virtude da magia que lhe é inerente. Desse modo, ressalta o aspecto dionisíaco e o aspecto apolíneo dessa invenção dos humanos.

Referente ao primeiro (dionisíaco), aponta a arte como um caminho do indivíduo para a plenitude; para a expressão do desejo, no sentido de se identificar com aquilo que ele não é. Referente ao segundo (apolíneo), aponta seu elemento de divertimento e satisfação presente quando o observador não se identifica e até se distancia do que está vendo representado; escapa ao poder direto com que a realidade o subjuga, mediante a representação do real, libertando-se, na arte, do esmagamento em que se acha no cotidiano. Nesse paradoxo, consiste o ato criador, o qual não consta somente de um estado de inspiração embriagante, mas também do resultado de um trabalho consciente e racional de dominação da realidade.

Ao longo da história, registra-se a coexistência de teorizações acerca da criação artística referentes ao sublime e ao epistêmico; como produção do inconsciente, efeito da sublimação de pulsões sexuais ${ }^{1}$, e como produção da consciência, fruto de um trabalho cognitivo calcado na descoberta e na invenção. Neste último caso, refere-se ao trabalho realizado pela ativação sistêmica, integrada e coerente de recursos intelectuais como percepção, memória, atenção, pensamento, resolução de problemas, expressão, comunicação, criação, imaginação, entre outros, os quais

${ }^{1}$ Referimo-nos aqui à concepção psicanalítica, vigente na obra de Sigmund Freud nas primeiras décadas do século XX. 
decorrem da transmissão cultural entre as gerações, bem como das interações sociais e interculturais.

Quer-se aqui destacar a linha de pensamento da Cognição Imaginativa, a qual contribui para a mudança de concepção de arte, enquanto forma de linguagem, para uma concepção que a coloca como resultado de operações cognitivas de imagens esquemáticas. Nesse sentido, sua transmissão não se daria por comunicação, mas por metáfora - não no sentido linguístico, mas no sentido imagético (NEVES, 2017).

O historiador de arte-educação Arthur Efland tem estudado amplamente a metáfora como cognição; como elemento que constrói ligações as quais permitem a estruturação do conhecimento em diferentes domínios, estabelecendo conexões entre coisas aparentemente não relacionadas. Desse modo, considerando a metáfora como um dos elementos mais importantes no trabalho de buscar compreender, parcialmente, o que não se pode compreender na totalidade, sobretudo ao que se refere a nossos sentimentos, experiências estéticas, práticas morais e consciências espirituais (EFLAND, 2004).

Nessa linha de pensamento, o termo "imaginativo" vem compreendido como uma classe específica de operações cognitivas. A imaginação não seria uma operação cognitiva, mas o resultado de ações cognitivas que permitem aos indivíduos construir significados que geralmente dependem menos das formas de pensamentos convencionais regidos por regras comunicacionais. Complementando com Pimentel (2016, p.12):

A palavra imagem não tem somente a conotação visual, mas remete à imaginação. Considera-se que várias são as formas de se pensar uma imagem, seja ela sonora, gestual ou gráfica. A linguagem não substitui o pensamento em imagem, sendo apenas uma forma de comunicá-la. É preciso distinguir o que seja o pensamento imagético e o que seja a comunicação via imagens, uma vez que arte e comunicação são duas áreas de conhecimento proximais, porém, distintas. Na proposta da Cognição Imaginativa, Arte deve ser compreendida como um meio de destruir automatismos perceptivos, não se resumindo à linguagem.

A imaginação, assim como sentimentos e emoções, significa um tema que sofre resistência no âmbito das ciências que tratam da cognição. Desde Platão a 
atividade imaginativa, como a inspiração do artista, era considerada duvidosa por não se referir à realidade objetiva ou mesmo pelo fato de se ver submetida a uma origem divina. O pensamento racionalista do século XVII propõe regras à direção da mente em defesa das construções da imaginação, opostas à verdade, mas passa a imaginação a ser amplamente discutida no campo literário e filosófico ao longo dos séculos XVIII e XIX. Kant, na Crítica da Razão Pura (XVIII) reconhece-a como uma faculdade produtiva da cognição, a qual permitiria à mente a criação de outra natureza a partir do conjunto de imagens proporcionadas pela natureza real. Entretanto, no final do século XIX e início do século XX, as influências do positivismo geram desinteresse sobre esse objeto de estudo, uma vez que trata de um elemento não diretamente observável no comportamento humano.

Em 1934, John Dewey (2010), em Arte como experiência, destaca o fato de a imaginação significar o ponto em que a mente entra em contato com o mundo, quando coisas velhas e conhecidas se fazem novas na experiência.

Em 1930, Vygotsky (ÁLVAREZ; DEL RIO, 2007) apresenta uma ideia sobre a imaginação e a criatividade na infância e na adolescência. Defendendo que a imaginação significa uma importante função para o desenvolvimento e o comportamento humanos. Constituindo, portanto, uma condição absolutamente necessária para quase toda função cognitiva do ser humano, uma vez que tal função permite o alargamento das possibilidades do pensamento, de modo a atingir instâncias e proposições nem sempre diretamente relacionadas com a experiência. Descreve um complexo processo de dissociação seguido de agrupamento de características isoladas, assimiladas na percepção e organizadas em um novo sentido. Tal processo, segundo o autor, é de enorme importância no desenvolvimento intelectual humano, que serve de base ao pensamento abstrato e à compreensão metafórica.

Essas aberturas teóricas para o tema permitiram que, na $2^{\mathrm{a}}$ metade do século $\mathrm{XX}$, a psicologia apresentasse estudos que incluem as imagens mentais como um campo da cognição. Nesse sentido, o presente ensaio ${ }^{2}$ pretende apresentar uma abordagem que propõe pensar a arte como "uma ação cognitiva imaginativa que integra conhecimento, construção e expressão, (...) uma atividade humana que con-

2 Este ensaio diz respeito a um dos capítulos de tese de doutorado, inédita, defendida na Faculdade de Educação da Universidade Federal de Minas Gerais - UFMG. 
siste em transformar a natureza ou matéria em cultura" (PIMENTEL, 2013, p. 101) e, desse modo, busca contribuir com elementos desse campo para as discussões acerca do teatro na educação.

\section{COGNIÇÃO IMAGINATIVA}

Pode-se dizer, a Cognição Imaginativa significa uma linha de pensamento a qual considera que a imaginação representa o único "espaço" possível de construção de conhecimento, em qualquer área. Estando os outros "espaços" tomados por relações, registros memoriais, automatismos, etc., é no espaço imaginativo que novas formas podem se construir, lançando-se mão do que existe nos demais. Um circuito que se movimenta a partir do momento em que o construído se fixa e migra - para memória, relações ou automatismos, dando lugar para que novas construções possam ocorrer (NEVES, 2014).

Efland (2005, p.183-184) parte da proposta de pensar a imaginação como ação e poder de formar imagens mentais do que não se vê, de fato, presente em nossos sentidos ou que não tenha sido experimentado. Ou, ainda, o poder de criar novas ideias ou imagens por meio da combinação e reorganização de experiências prévias. Trata-se de um processo cognitivo que permite aos indivíduos organizar ou reorganizar imagens, combinar ou recombinar símbolos - como nas produções narrativas ou na criação de metáforas. Sobre essas últimas, o autor recorre, sobretudo ao trabalho linguístico de George Lakoff e Mark Johnson, somados ao conceito de esquemas proposto por Jean Piaget.

Lakoff e Johnson (2007) ressaltam os fundamentos cognitivos de atividades mentais aparentemente abstratas, como a categorização e a metáfora - metáfora conceitual. Defendem a presença de evidências que propõem a existência do que denominaram como um nível de operações cognitivas imagem-esquemáticas, a partir de estruturas baseadas em imagens derivadas da experiência corpórea e perceptiva cotidiana.

Poder-se-ia dizer que figura a noção piagetiana de esquema, enquanto conjunto de estruturas mentais pelas quais os indivíduos interpretam e organizam int- 
electualmente as informações. Entretanto, esses autores preveem um rol contínuo para as imagens-esquema na cognição, não respondendo a um sistema evolutivo como propõe Jean Piaget ${ }^{3}$, ao configurar-se num esquema que estabelece as bases das formas de pensamento proposicional e não proposicional - a categorização, a razão abstrata, imagens mentais, metáfora e narrativa.

As imagens-esquema não seriam, portanto, imagens que recordamos de percepções anteriores, mas estruturas cognitivas que derivam de uma variedade de imagens produzidas a partir da relação do corpo com o meio físico e a cultura. Uma vez estabelecidas, essas imagens-esquema mostram-se potencialmente constituídas para a elaboração metafórica, de forma que a ideia ou conceito possa transporse para outro campo que não o primeiro, concreto.

A experiência do corpo, por exemplo, com a orientação espacial e com o limite em relação ao ambiente, a partir da pele, permite a construção de "dentro/fora" ou "cima/baixo/lado", oportunizando ideias de caráter abstrato - estar para cima, animado; apoiar alguém, estar ao seu lado. Tratando-se aí, portanto, do estabelecimento de esquemas que dão bases para a elaboração de outros conceitos por meio da metáfora. Ou seja, as imagens-esquema que emergem de sensações e percepções corporais alcançam o âmbito mental, epistêmico ou lógico da cognição, ensejando que os atos de cognição, como a categorização e a metáfora, tornem-se possíveis. Desse modo, para esses autores, a razão abstrata inicia-se com a formação de imagens-esquema na experiência corporal - cotidiana ou provocada.

Lakoff e Johnson (2007) destacam que as categorias de nosso pensamento cotidiano revelam-se amplamente metafóricas, que nosso raciocínio cotidiano supõe implicações e interferências metafóricas e, ainda, que a racionalidade ordinária é imaginativa por sua própria natureza.

A partir de uma concepção construtivista da metáfora, estes dois autores defendem que as expressões metafóricas não constituem matérias de linguagem, mas formas de pensamento baseadas em conceitos da realidade - tornando-se realidade no sentido intrassubjetivo. Verifica-se, desse modo, a importância vital das metáforas para o funcionamento da mente humana; pois, não se vinculando apenas à lin-

${ }^{3}$ Refere-se ao curso evolutivo dos estágios: sensório-motor, pré-operacional, operacional concreto e operacional formal. 
guagem, mas também à função cognitiva, conclui-se que sem sua atuação constante, o pensamento em si mesmo tornar-se-ia impossível. Obtém-se assim, portanto, uma razão por que mente e corpo encontram-se indissociáveis.

Referenciando-se nessa concepção, Arthur Efland (2005) afirma que a metáfora aparece em todos os domínios do conhecimento, mas destaca a arte como o domínio onde as experiências de ações metafóricas da mente significam a via de construção de sentidos. Para o autor, não é a metáfora por si só o que distingue a experiência artística das outras experiências, mas a excelência dos níveis metafóricos de imaginação presente nessa área de conhecimento, bem como seu vínculo com a estética.

Com base nestes pressupostos, conclui-se que a prática artística potencializa o repertório imagético daquele que a experiência, gerando maior capacidade cognitiva em quaisquer práticas do conhecimento. "Somente nas artes os processos e produtos da imaginação se encontram e se exploram com plena consciência; se convertem em objetos de investigação, diferentemente das ciências, onde as metáforas usadas ficam ocultas" (EFLAND, 2005, p.206-207).

Em suma, a partir das referências que orientam esta linha de pensamento, a arte pode ser compreendida como uma atividade calcada em elementos cognitivos, uma vez que apresenta como base de construção de sentidos a imaginação - ação que convoca esquemas articulados pelo recurso de pensamento da metáfora, a qual emana da percepção e da experiência corpórea.

\section{GLOBALIZAÇÃO E PRODUÇÃO DE CONHECIMENTO}

Além de destacar a excelência dos níveis metafóricos de imaginação presente nessa área de conhecimento, bem como seu vínculo com a estética, Efland também ressalta (2005) o aspecto da integração dos conhecimentos por meio da arte. E aponta que, ao fruir uma obra, o aprendiz precisa recorrer a diversos caminhos investigativos e relacionar os conhecimentos de modo a compreender o tempo, espaço e circunstância política e social a que a obra se refere. Desse modo, como a obra de arte convoca a integração dos conhecimentos, este autor sugere que as 
artes deveriam centrar-se nos currículos escolares, como elemento que intersecciona os demais.

A compreensão de uma obra de arte é feita em relação aos domínios social e cultural de que se faz parte e, reciprocamente, a compreensão da obra também ajuda o estudante a capturar os mundos cultural e social que se reflete. Isso sugere que obras de arte poderiam servir como pontos de integração entre vários campos do conhecimento, uma vez que uma obra estrategicamente escolhida poderia servir como base comum sobre a qual eles (os conhecimentos) se sobrepõem e se fundem à medida que os alunos constroem sua compreensão sobre a obra ${ }^{4}$. (EFLAND, 2005, p. 223. Tradução nossa)

Embora o autor em seus trabalhos se refira mais diretamente às obras plásticas, o mesmo deve-se pensar a partir de outras modalidades artísticas, como o teatro. Assistir a um espetáculo teatral requer a relação entre saberes de outra natureza, uma vez que propõe-se à plateia uma construção singular de tempo, espaço, situação e circunstância. Do mesmo modo, propõe-se ao ator esta construção, a qual passa também pela dimensão do corpo com todos os seus recursos.

A integração dos conhecimentos, em especial, constitui tema amplamente discutido por Fernando Hernández ${ }^{5}$, professor titular da Faculdade de Belas Artes da Universidade de Barcelona, na Espanha. Chamou ensino globalizado (HERNÁNDEZ; VENTURA, 1998) aquele em que a intenção consiste em que o aluno globalize os conteúdos e as aprendizagens, ou seja, estabeleça relações. Desse modo, centra-se na forma de organizar os diferentes saberes, tendo como desafio a articulação da aprendizagem individual com os conteúdos das diferentes disciplinas, no caso da escola.

Para estudar essa noção de globalização em relação à problemática dos saberes, Hernández, tendo como referência principal os autores Roland Barthes e Edgar Morin, parte de uma experiência com professores da Escola Pompeu Fabra

\footnotetext{
4 Cf. o trecho original: La comprensión de una obra de arte requiere que se haga en relación con los reinos social y cultural de los que forma parte, y, recíprocamente, la comprensión de la obra también ayuda al estudiante a captar los mundos cultural y social que refleja. Este sugiere que las obras de arte clave podrían servir como puntos de integración entre varios campos de conocimiento, ya que una obra escogida estratégicamente podría servir como la base común sobre la que se traslapan y se funden a medida que los estudiantes construyen su comprensión de la obra. (EFLAND, 2005, p. 223)

5 Efland e Hernández, autores que apresentam divergências no campo teórico, aqui são lidos como complementares no que tange à ideia da arte como globalizadora dos conhecimentos.
} 
(escola pública de Barcelona), em que se instituiu uma mudança de paradigma curricular a partir de Projetos de Trabalho.

Propõe que o foco do ensino globalizado consiste em que o aluno aprenda a articular os pontos de vista disjuntos do saber num ciclo ativo; superando o sentido de acumulação de saberes em torno de um tema e enfrentando-se com a necessidade de criar novos objetos de saber, a partir dos referenciais que se faça necessário incorporar para cada um deles (HERNÁNDEZ; VENTURA, 1998).

Portanto, o tema ou o problema é o que reclama a convergência de conhecimentos. Sua função articuladora consiste em estabelecer relações compreensivas, que possibilitem novas convergências geradoras. Desse modo, mais que uma atitude interdisciplinar ou transdisciplinar, significa uma posição que pretende promover o desenvolvimento de um conhecimento relacional enquanto atitude compreensiva das complexidades do próprio conhecimento humano.

$\mathrm{Na}$ intenção de esclarecer por que se faz necessário desenvolver propostas globalizadoras nas aprendizagens escolares, Hernández (1998) destaca que a impossibilidade de tudo conhecer originou a necessidade de aprender como se relaciona o que se conhece, e de estabelecer sua vinculação com o que o aluno pode chegar a conhecer.

Entretanto a ideia de globalização do conhecimento, muitas vezes, torna-se um tanto confusa quando de sua realização. Talvez porque se parta da ideia de que o professor é quem promove a globalização; sendo que, de fato, é o aluno quem a realiza. É o estudante quem deve ter oportunidades de ensino que o permitam aprender a encontrar e estabelecer conexões na informação.

Logo, propostas globalizadas não devem partir do professor como aquele que decide o que se vai aprender e que fontes de informação serão estudadas. O objetivo da globalização, como atividade de integração de conhecimentos, pede que os alunos estabeleçam relações com muitos aspectos de seus conhecimentos anteriores, enquanto que, ao próprio tempo, vai integrando novos conhecimentos significativos.

Partindo dessa concepção, Hernández (1998) discute a estruturação de currículos, bem como modos de organização do projeto escolar, a fim de possibilitar esse nível de aprendizagem. Entretanto, na impossibilidade de mudar-se um paradigma 
de trabalho institucional, pode-se pensar também em tipos de atividades que convoquem a globalização do conhecimento; ou seja, atividades que promovam no aluno a mobilização das informações obtidas nas várias áreas que compõem as disciplinas escolares, de modo a articulá-las para a construção de um novo saber.

Pode-se pensar a atividade artística como globalizadora em sua essência, no aspecto da fruição e, sobretudo, no fazer. Ao se deparar com uma obra plástica ou cênica, convocam-se saberes de diversas áreas para que se consiga dar sentido àquela experiência. Elementos da história, das ciências biológicas, entre outros, bem como os elementos do cotidiano, veem-se automaticamente articulados para tal.

Mas, acima de tudo, no fazer artístico convocam-se elementos de diversos campos do saber para se construir uma obra - isso para o artista ou para um aluno convidado a construir, nesse campo da metáfora, algo que expresse, transmita ou sensibilize outros sujeitos com possível acesso à obra.

Soma-se a isso o novo que a experiência artística pode apresentar. Assim como as demais áreas do conhecimento, a arte fornece palavras e imagens; bem como fornece imagens a partir de palavras e palavras a partir de imagens. Além de ampliar o repertório simbólico do sujeito no impacto desse encontro, segue fomentando pensamento e linguagem pela via das interpretações e busca de sentido.

Convocamos novamente o pensamento de Vygotsky, para quem a percepção, a emoção, criatividade e imaginação são tratados como processos psicológicos em estreita relação com a arte (VYGOTSKY, 2001). Segundo o autor, o encontro com a arte proporciona, a partir de processos de apropriação, generalização e objetivação, novas organizações psíquicas, possibilitando a cada um a elevação à condição de indivíduo singular. Processo este que provoca a organização da consciência a partir de leis extraídas das experiências, do modo a alterar a relação do sujeito com o mundo na medida em que eleva as representações das coisas e suas relações a níveis mais complexos, ampliando o significado e o domínio do sujeito sobre os objetos, sobre as relações sociais e sobre si mesmo.

Com relação ao efeito cognitivo da arte, Vygotsky (2004) destaca: 
com novos olhos, a generalizar e unificar fatos amiúde inteiramente dispersos. É que, como qualquer vivência intensa, a vivência estética cria uma atitude muito sensível para os atos posteriores e, evidentemente, nunca passa sem deixar vestígios para o nosso comportamento. (p. 342).

Num trânsito de âmbito intersubjetivo para o intrassubjetivo, a arte, nessa perspectiva, pode ser pensada como um produto cultural que significa a cristalização de complexas atividades mentais as quais podem então ser apropriadas pelos demais sujeitos. Desse modo, exprime a condição histórico cultural da sociedade que Ihe dá origem e materializa, no objeto cultural produzido, características psicológicas complexas, ao mesmo tempo em que possibilita a apropriação de tais características pelos sujeitos. Ou seja, a arte enquanto objeto cultural produzido sob dada técnica, nesse sentido, não se apresenta como fruto de um único sujeito, o artista, mas como componente de uma transformação cognitiva que nos permite observar a evolução, por exemplo, de um desenho egípcio ao domínio da técnica da perspectiva.

Assim, de acordo com Vygotsky, podemos dizer que ao se produzir arte a ao dela se apropriar, tem-se a possibilidade de transformação e desenvolvimento de funções psicológicas superiores, as quais ocorrem no nível da consciência, a partir da síntese dessas funções, pautada em vínculos hierárquicos semânticos, construídos com base na apropriação dos significados das imagens (sonoras, gestuais ou gráficas) e das palavras.

Tal peculiaridade da experiência artística é significativa em qualquer especificidade (dança, música, artes cênicas e visuais), porém cabe ressaltar que o teatro talvez enseje maiores possibilidades, em função dos múltiplos recursos do humano que utiliza. Ao se construir um personagem e uma cena, o tempo, o espaço, o clima, sentimentos e ideias são comunicados ao público. Para tal, o corpo em cena, a partir da ação - do movimento e/ou da palavra - utiliza conceitos e conhecimentos para elaborar algo a transmitir ou como transmitir. $O$ ator utiliza saberes adquiridos sobre o mundo, e saberes sobre si, para sua construção cênica. Além disso, os recursos externos a ele - o cenário, o figurino e a dramaturgia - também são construídos a partir da relação entre os conhecimentos adquiridos pelos sujeitos. 
O teatro na escola, no formato de uma peça, esquete ou de jogo, pode ser pensado como uma atividade globalizadora, a partir dos recursos de apropriação, generalização e objetivação, no sentido de convocar o estabelecimento de relações entre os diferentes saberes (escolares e não escolares), organizá-los e utilizá-los na solução de um problema - a criação cênica.

\section{TEATRO E CONHECIMENTO}

Pensando-se nas diversas formas e características expressivas em arte, a partir do que veio exposto até aqui, pode-se dizer que todas as artes configuram experiências de cognição, embora difiram nos aspectos alusivos ao privilégio de um ou mais elementos sensoriais. Partindo da ideia de imagem como não apenas visualidade, gesto, som, cor, gosto e cheiro configuram imagens de mesmo nível de sentido. A dança oferece experiências com o movimento; a música com os recursos rítmicos, melódicos, harmônicos e poéticos.

Mas este trabalho privilegia as possibilidades presentes no teatro, enquanto modalidade artística que permite uma gama de experiências, uma vez que se relaciona com o texto dramatúrgico; com a utilização da voz em volumes, timbres e intenções variadas; com o movimento corporal calcado na intenção; com a cenografia; e com a contracena.

Teatro se refere a um espaço vazio circundado por coisas; e que habita seres e coisas, proporciona sensações e percepções - similares ou singulares - àquele que observa. Portanto, possui dimensões objetivas e subjetivas. E mesmo quando não traz uma demarcação concreta (física), vê-se delimitado pela intenção e pela conivência do que é a cena e do que é o fora de cena - plateia e cena oculta.

Mas, é esse vazio que produz a ação - a representação, a interpretação e a imaginação. Algo está prestes a acontecer; alguém vai apresentar esse acontecimento; e outro vai significá-lo.

"O tablado-teatro é um espaço-tempo: existe como tal e conserva suas propriedades enquanto estiverem presentes os espectadores, ou forem supostos (como nos ensaios)" (BOAL, 2002, p.33). Boal destaca o fato de que o teatro existe na sub- 
jetividade daquele que o pratica (e no momento de praticá-lo) e não na objetividade de palcos, cenários e figurinos. Acima do tablado, e mesmo da plateia, encontra-se o ator. "Nele nasce o teatro. Ele é o Teatro. Todos nós somos Teatro" (BOAL, 2002, p. 33).

Teatro significa uma forma de conhecimento (BOAL, 2002). Possui propriedades gnosiológicas, isto é, que estimulam o saber e o descobrir, o conhecimento e o reconhecimento - propriedades que induzem ao aprendizado.

Para Grotowski (1992), ao se fazer teatro, realiza-se o ato estético. E nessa experiência, como atores ou como espectadores, ampliamos nossa visão sobre o mundo e nos treinamos na percepção de nossa própria individualidade. Ao desenvolver a dimensão poética, a arte (teatro) ensina que é possível transformar continuamente a existência, trazendo, ao mesmo tempo, a força e a flexibilização necessária para a proposição de novos caminhos.

Peter Brook proclama que teatro é vida. Em seu importante livro A porta aberta (2011), o autor destaca o espaço vazio, proposto pelo teatro, onde inserimos a representação da vida.

O vazio desse espaço nos mobiliza para a criação de modos e formas, distintos da lógica da realidade, e nos permite, por meio da arte da interpretação, apresentar longos trechos da existência condensados em um instante. Seria, portanto, o vazio do palco que promoveria o teatro.

Vamos ao teatro para um encontro com a vida, mas se não houver diferença entre a vida lá fora e a vida em cena, o teatro não terá sentido. Não há razão para fazê-lo. Se aceitarmos, porém, que a vida no teatro é mais visível, mais vívida do que lá fora, então veremos que é a mesma coisa e, ao mesmo tempo, um tanto diferente. Convém acrescentar algumas particularidades. A vida no teatro é mais compreensível e intensa porque é mais concentrada. A limitação do espaço e a compressão do tempo criam essa concentração. No fundo, é a vida, mas uma vida em forma mais concentrada, mais condensada no tempo e no espaço (BROOK, 2011, p. 8-9).

No espaço estético-teatral o tempo pode correr diferente, pode retornar; e o que é inanimado ou morto pode ocupar a vida. "Trata-se de um espaço dicotômico e assíncrono - ele é o que é e é o que foi ou o que poderia ter sido, ou poderá vir a ser. É no presente e também é no passado lembrado ou no futuro 
imaginado" (BOAL, 2002, p. 35). Portanto, esse espaço possui a plasticidade do sonho. E apresenta uma dimensão afetiva que desperta em cada espectador, com formas e intensidades diferentes, novas emoções, sensações, pensamentos e lembranças renovadas; além de aspectos que fogem à sua consciência. Mantendo-o, portanto, sujeito, muitas vezes distante do seu objeto.

Cena e plateia ocupam o mesmo espaço, respiram o mesmo ar, no mesmo dia e horário. Entretanto, em cena se cria a ilusão de um mundo estranho e distante, muitas vezes, para o qual a plateia se dispõe a transpor. O ator é quem convida.

$\mathrm{O}$ ator é aquele que se dispõe a ir um pouco além. Dispõe-se a se ver em cena sendo outra pessoa, a partir da emissão do discurso determinado por um outro - o autor, mantendo uma relação binária com a plateia. Se existe teatro, é porque existem atores - estes significam o começo e o fim da arte teatral.

\section{EM CENA, O ATOR!}

São várias as funções ocupadas para uma construção cênica teatral, mas aqui quer se destacar a experiência cênica de atuação. Em qualquer forma de teatro, o ator 6 é quem mantém sempre uma relação de atração e repulsão; de identificação e afastamento com o personagem que interpreta. No teatro stanilavskiano ${ }^{7}$, por exemplo, o ator sabe que é ator, mas procura ignorar conscientemente a presença dos espectadores. Já no teatro brechtiano ${ }^{8}$, o ator tem perfeita consciência da presença dos espectadores, que são, por ele, transformados em verdadeiros interlocutores (DESGRANGES, 2006). Maior ou menor, essa distância sempre existe.

Entretanto, independentemente da proposta cênica, o ator em cena, mergulhado em suas emoções, mantém inteira consciência de suas ações e controle sobre si mesmo. Muito embora, a cada personagem, algo de novo instala-se nesse ator efeito de mostrar-se em cena. $\mathrm{O}$ ator age e se observa agindo, mostra e se observa

\footnotetext{
$6 \mathrm{O}$ termo ator vem aqui utilizado para designar os atuantes de todos os gêneros. A escolha pelo gênero neutro diz respeito à simplificação da escrita e não à adesão a uma prática discursiva sexista.

${ }^{7}$ Referente às propostas cênicas de Stanislavski.

8 Referente às propostas cênicas de Brecht.
} 
mostrando, fala e ouve o que diz. Essa fissão, também possível em outros espaços, em cena torna-se inevitável.

Talvez o teatro seja, das artes, a mais complexa em sua prática porque requer a coexistência de três conexões - o vínculo do ator com sua vida interior, com seus colegas e com o público (BROOK, 2011). Mas a discussão dessa posição na cena não surge com a origem do teatro. Possivelmente, apenas no século XVII, quando o Abade D’Aubignac escreve a Prática de Teatro propondo, entre alguns aspectos, a distinção do ator e o personagem, passando a pensar na arte específica da representação.

Já no século XVIII, Diderot, em Paradoxo sobre o Comediante (ator), dada tal separação, permite-nos pensar sobre o trabalho cognitivo do ator e o que significa o personagem nesse trabalho. Para Diderot (2006), os maiores atores, mais dotados de imaginação, significam aqueles que usam logicamente a razão e dominam seus gestos e postura no ato de representar. São aqueles que menos se apresentam sensíveis; que sabem representar a sensibilidade humana, mas não exprimem sua própria sensibilidade. Portanto, o ator e o personagem que ele representa guardam devida distância, embora sua ação, no palco, seja de certo modo "vivida" pelo mesmo com intensidade. A experiência sensível deve partir, então, do espectador que vai vivenciar a catarse (no caso das tragédias) ou o prazer (no caso das comédias).

Assim, Diderot (2006) aponta que o ator precisa de técnica, de capacidade de observação do mundo a seu redor e de seu mundo interior. E, desse modo, seja capaz de emprestar seu gesto - que é seu e não seu - para apresentar a ação do personagem, de modo que ocorra verossimilhança passível de transmitir aquele instante como verdade.

Mas, quem pode ser ator? Segundo Boal, somos todos artistas e "fazendo teatro, aprendemos a ver aquilo que nos salta aos olhos, mas que somos incapazes de ver, tão habituados estamos apenas a olhar. O que nos é familiar torna-se invisível: fazer teatro, ao contrário, ilumina o palco da nossa vida cotidiana. Atores so- 
mos todos nós, e cidadão não é aquele que vive em sociedade: é aquele que a transforma!"9

Com influências brechtianas e freireanas ${ }^{10}$, Boal destacou e usou a potência política do teatro. Propõe o Teatro do Oprimido (T.O.) e transforma o espectador em ator e transpõe o teatro para espaços sociais diversos - comunidades, hospitais, escolas, presídios, entre outros. Boal provocou os sujeitos, esteticamente, para a reflexão e ação acerca da opressão, a partir da cena.

O T.O. consiste num Método Estético ${ }^{11}$ que sistematiza Exercícios, Jogos e Técnicas Teatrais, que objetivam a desmecanização física e intelectual de seus praticantes, e a democratização do teatro. O T.O. cria condições práticas para que o oprimido se aproprie dos meios de produzir teatro e, assim, amplie suas possibilidades de expressão. Além disso, estabelece uma comunicação direta, ativa e propositiva entre espectadores e atores. Compõem a Metodologia: Teatro Jornal, Teatro Imagem, Teatro Invisível, Teatro-Fórum, Teatro Legislativo, Arco-Íris do Desejo (Método Boal de Teatro e Terapia - um conjunto de técnicas terapêuticas e teatrais, adequadas para a análise de questões interpessoais e/ou intrapessoais).

Em um espetáculo de Teatro-Fórum o espectador adquire voz e movimento, som e cor, e pode assim exprimir desejos e ideias - o espectador torna-se ator no palco para tornar-se ator na sociedade.

Pode-se dizer, o Teatro-Fórum corresponde à própria dramatização da Pedagogia do Oprimido, explicitada por Paulo Freire; um ensaio das ações propostas por essa pedagogia crítica e entusiasta. Tanto Freire quanto Boal propõem ideologias por meio do uso de suas metodologias, que associam ao ensino as experiências vividas, e ao trabalho, a pedagogia e a política. Ambos os autores dão ênfase às condições de uma prática educativa, defendendo a ideia de que educar é conhecer, é ler, e interpretar o mundo para poder transformá-lo. Boal traz para o corpo a ideia que Freire começou na palavra.

\footnotetext{
9 Mensagem proferida em 2009 em ocasião do Dia mundial do teatro. Disponível em: <http://www.itibrasil.org.br/?p=78>

10 Referente à Pedagogia do Oprimido, de Paulo Freire.

11 www.ctorio.org.brwww.ctorio.org.br
} 
Partindo de Boal, cada espectador é considerado um ator em potencial. Essa potencialidade, não reconhecida como natural, necessita ser estimulada para se tornar ação. Para se efetivar como ator, ou como espect-ator, Boal sugere que o participante deve se preparar com exercícios dramáticos que objetivem a ampliação da consciência do corpo e o desenvolvimento das capacidades criativas e expressivas. Desse modo, tal espectador pode transformar-se em protagonista da ação dramática, para, em seguida, utilizar em sua vida as ações que ensaiou na cena.

\section{POR QUE TEATRO NA EDUCAÇÃO?}

Seja a partir de um jogo teatral que vise à solução de um problema cênico, seja na criação de um personagem, cena, espetáculo ou ação social, o teatro, na perspectiva aqui abordada, pode ser compreendido como uma experiência estética e cognitiva. Experiência esta que convoca e produz a Cognição Imaginativa, ao provocar ações geradoras de imagens-esquemas e promotoras de metáforas; ou seja, uma experiência capaz de ampliar os modos de conhecer - elemento central do projeto educativo.

A criação cênica, pode-se dizer, consiste na construção de uma nova estrutura concreta, um novo quadro de realidade ou ainda a corporificação criativa de uma ideia. Portanto, um processo singular de apropriação, generalização e objetivação, na possibilidade de novas organizações psíquicas e, consequentemente, na alteração da posição do sujeito diante das representações das coisas e suas relações, ampliando o significado e o domínio do sujeito sobre os objetos, sobre as relações sociais e sobre si mesmo. Desse modo, provocando a constituição de um produto cultural, o qual significa a cristalização de atividades mentais do ator, as quais podem então ser apropriadas pelos demais sujeitos da cena - no palco ou na plateia.

O processo criativo em teatro configura-se ainda como um movimento globalizador de conhecimentos. Pode-se dizer, a transposição para o corpo da ideia, em experiência, propõe o entrelaçamento conjunto de conhecimentos possíveis, além daqueles que se produzem no ato, no diálogo com as plateias. 


\section{CONSIDERAÇÕES FINAIS}

Qual a importância da presença do teatro junto ao rol dos conhecimentos transmitidos nos espaços educativos? As respostas são muitas, advindas de diversos campos de saber, para além, inclusive, do campo das artes.

Este trabalho buscou apresentar uma abordagem que propõe pensar a experiência artística como ação cognitiva, destacando-se elementos desse campo para as discussões referentes à arte, em especial o teatro, na educação.

Foram apresentados pressupostos teóricos contemporâneos acerca da arte como cognição, acerca da compreensão do processo criativo como ação globalizadora de conhecimentos, bem como a imaginação como produto e processo de uma materialização estética constituída pela organização singular dos recursos simbólicos socialmente construídos.

Na experiência cênica é possível se ver em cena e apreender outros modos de ver-se no mundo. É possível aprender sobre o mundo e, ao mesmo tempo, atribuir sentido a ele, uma vez que se refere a um espaço de conhecimento. Também é possível realizar, enquanto atividade artística, o exercício de promover a articulação e organização dos diversos saberes adquiridos, ao longo da vida, para a criação de uma solução cênica. Além de possibilitar a ação, em amplas dimensões, geradora de imagens-esquemas imprescindíveis à construção das bases da competência metafórica e imaginativa do pensamento, imprescindíveis à construção do conhecimento.

\section{RREFERÊNCIAS}

ÁLVAREZ, Amelia.; DEL RIO, Pablo. Escritos sobre arte y educación creativa de Lev. S. Vygotski. Madrid: Fundación Infancia y aprendizaje, 2007.

BOAL, Augusto. O Arco-íris do Desejo: método Boal de Teatro e Terapia. $2^{\mathrm{a}}$ ed. Rio de Janeiro: Civilização Brasileira, 2002.

BROOK, Peter. A porta aberta. Rio de Janeiro: Civilização Brasileira, 2011. CTO Rio - Centro de Teatro do Oprimido Rio de Janeiro. Disponível em: <http://ctorio.org.brhttp://ctorio.org.br> Acesso em: 21 non. 2017. 
DESGRANGES, Flávio. Pedagogia do teatro: provocações e dialogismos. São Paulo: Hucitec, 2006.

DEWEY, John. Arte como Experiência. Trad. Vera Ribeiro. São Paulo: Martins Fontes, 2010.

DIDEROT, Denis. Paradoxo sobre o comediante. Coleção Grandes Obras do Pensamento Universal. São Paulo: Editora Escala, 2006.

EFLAND, Arthur D. Arte y cognición: la integración de las artes en el currículum. Barcelona: Octaedro EUB (Ediciones Universitarias de Barcelona), 2004.

EFLAND, Arthur. D. Imaginação na cognição: o propósito da arte. In: BARBOSA, Ana Mae (Org.) Arte/Educação contemporânea: consonâncias internacionais. São Paulo: Cortez, 2005. p.318-345.

GROTOWSKI, Jerzy. Em busca de um teatro pobre. Rio de Janeiro: Civilização Brasileira, 1992.

HERNÁNDEZ, Fernando; VENTURA, Monserrat. A organização do currículo por projetos de trabalho: o conhecimento é um caleidoscópio. $5^{\mathrm{a}}$ ed. Porto Alegre: ARTMED, 1998.

HERNÁNDEZ, Fernando. Transgressão e Mudança na Educação: os projetos de trabalho. Trad. Jussara Haubert Rodrigues. Porto Alegre: ArtMed, 1998.

LAKOFF, George; JOHNSON, Mark. Metáforas de la vida cotidiana. $7^{\mathrm{a}}$ ed. Madrid: Ediciones Cátedra, 2007.

MITHEN, Steven. A pré-história da mente: uma busca das origens da arte, da religião e da ciência. São Paulo: Editora UNESSP, 2002.

NEVES, Libéria Rodrigues. Contribuições da Arte ao Atendimento Educacional Especializado e à Inclusão Escolar. Rev. Bras. Educ. Espec., Marilia, v. 23, n. 4, p. 489-504, 2017.

NEVES, Libéria Rodrigues. Teatro-Conversação na Escola: o uso do Teatro na Conversação na mediação de conflitos na Educação. BH, MG, 2014. Tese (Doutorado em Educação) - Universidade Federal de Minas Gerais, UFMG, 2014.

PIMENTEL, Lúcia Gouvêa. A Cognição Imaginativa como projeto de formação do professor@/artista. In: XXVI CONFAEB - Congresso Nacional da Federação de Arte/ Educadores do Brasil. Boa Vista, 2016, p. 11-21.

PIMENTEL, Lúcia Gouvêa. Cognição Imaginativa. Pós: Revista do Programa de Pós-Graduação em Artes da Escola de Belas Artes da UFMG, v. 3, n.6, p.96-104. 2013. 
VYGOTSKY, Lev S. Psicologia da arte. São Paulo: Martins Fontes, 2001. VYGOTSKY, Lev S. Psicologia pedagógica. São Paulo: Martins Fontes, 2004.

Recebido em: 23-06-2018

Aprovado em: 18-032019 